\title{
Comunicação
}

\section{Participação do nitrogênio na indução de injúrias foliares e na eficácia do herbicida glyphosate ${ }^{1}$}

\author{
Saul Jorge Pinto de Carvalho ${ }^{2 *}$, Heryaldo Tarozzo Filho ${ }^{3}$, Ana Carolina Ribeiro Dias ${ }^{4}$, Marcelo Nicolai $^{4}$, \\ Pedro Jacob Christoffoleti ${ }^{5}$
}

\begin{abstract}
RESUMO
Com o objetivo de avaliar diferentes aspectos da participação do nitrogênio na indução de injúrias foliares e na eficácia do herbicida glyphosate, foram desenvolvidos três experimentos, sendo dois em casa de vegetação, com as espécies Avena strigosa e Ipomoea triloba + Sorghum halepense, e um em campo, com Brachiaria decumbens. Avaliou-se a aplicação de glyphosate combinado com ureia (U), com sulfato de amônio (SA) e com U+AS, além de fertilização prévia do solo com nitrogênio e pulverização de caldas concentradas com até $20 \%$ de N. A pulverização de caldas concentradas com até $20 \%$ de N não dessecou adequadamente as espécies A. strigosa e B. decumbens, provocando danos máximos de cerca de 30\%. A utilização de solução de SA ou de U+SA como veículo de pulverização do glyphosate elevou o controle de I. triloba. As soluções nitrogenadas aceleraram a atividade do glyphosate para dessecação de $S$. halepense, porém, sem diferenças visíveis aos 28 dias após aplicação. A escolha da dose adequada de glyphosate (1.800 $\mathrm{g} \mathrm{ha}^{-1}$ ) para dessecação de $B$. decumbens foi fundamental para obtenção de elevado controle, sendo que a única alternativa que elevou a eficácia da menor dose do produto foi a fertilização prévia do solo com 150 $\mathrm{kg} \mathrm{ha}^{-1}$ de SA.
\end{abstract}

Palavras-chave: Ipomoea triloba L., Sorghum halepense (L.) Pers., plantio direto, dessecação.

\section{ABSTRACT}

\section{Nitrogen participation in the induction of foliar injury and glyphosate efficacy}

Three experiments were carried out, two in greenhouse and one in the field to evaluate different aspects of nitrogen participation in the induction of leaf injuries and glyphosate efficacy. Glyphosate was applied in combination with urea (U), ammonium sulfate (AMS) and U+AMS; following N soil fertilization and spray solutions with $\mathrm{N}$ concentrations up to $20 \%$. Application of nitrogen spray solutions did not provide satisfactory desiccation of the different plant species, reaching maximum damage of about $30 \%$. The use of AMS or U+AMS as a spray vehicle for glyphosate application increased control of morning glory (Ipomoea triloba L.). Nitrogen solutions accelerated glyphosate-desiccation of Johnsongrass (Sorghum halepense L.), however with no visible differences at 28 days after application. The choice of adequate glyphosate rate $\left(1,800 \mathrm{~g} \mathrm{ha}^{-1}\right)$ for Brachiaria decumbens Stapf desiccation was fundamental for reaching high control, and the only alternative that enhanced the efficacy of glyphosate lower rate was the previous fertilization of the soil with $150 \mathrm{~kg} \mathrm{ha}^{-1}$ of ammonium sulfate.

Key words: Ipomoea triloba L., Sorghum halepense L., no-tillage, desiccation.

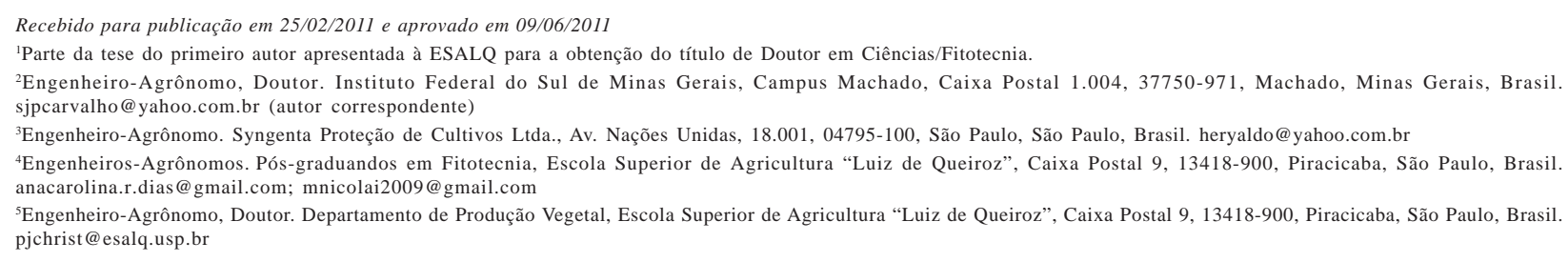




\section{INTRODUÇÃO}

Com intuito de promover a proteção do solo e do ambiente, tem-se observado maior preocupação do setor agrícola pela adoção de sistemas de cultivo denominados conservacionistas, tais como a semeadura direta (plantio direto), a adubação verde e o cultivo mínimo (Christoffoleti et al., 2007; Constantin et al., 2008). Nesses sistemas, herbicidas de manejo são aplicados antes da semeadura da cultura de interesse, para eliminação da cobertura vegetal e formação da palhada. Os herbicidas mais utilizados nesta prática são os dessecantes sem efeito residual, como o glyphosate, o paraquat e o diquat (Kozlowski, 2001; Timossi et al., 2006).

Em sistemas conservacionistas, o adequado controle químico das plantas de cobertura e da comunidade daninha contribui sobremaneira para o sucesso no estabelecimento das culturas agrícolas. Nos sistemas produtivos, as escolhas do tipo do herbicida e da dose têm particular importância e podem variar em razão da comunidade vegetal e do estádio fenológico das plantas (Timossi et al., 2006). Sabidamente, em diferentes espécies, a eficácia de um herbicida é função da absorção, da translocação, do metabolismo e da sensibilidade vegetal à determinada molécula e, ou, aos seus metabólitos (Silva et al., 2007).

Considerando-se a importância do glyphosate nos sistemas de plantio direto e, ou, de cultivo mínimo e para a agricultura mundial, estudos têm sido realizados com o objetivo de avaliar a contribuição de diferentes variáveis em sua eficácia, podendo-se destacar: dose (Jordan et al., 1997), volume de calda (Salas-Pino, 1996; Ramsdale et al., 2003), qualidade da água utilizada como veículo de pulverização (Thelen et al., 1995; Gauvrit, 2003), estádio fenológico das plantas daninhas (Durigan, 1992; Jordan et al., 1997) e atividade dos adjuvantes (Pratt et al., 2003; Nurse et al., 2008).

Mais recentemente, além da possibilidade de reduzir doses e número de intervenções com herbicidas, questões relacionadas com a interferência dos herbicidas dessecantes na ciclagem e nas perdas de nitrogênio do ambiente agrícola têm sido consideradas no manejo da cobertura vegetal no sistema de plantio direto (Argenta et al., 2001; Damin et al., 2008; Damin, 2009). A redução na disponibilidade de nitrogênio pode ter importantes implicações práticas, inclusive em futuras etapas do controle químico, uma vez que há evidências de que plantas com maior disponibilidade deste nutriente são controladas mais facilmente (Dickson et al., 1990; Cathcart et al., 2004).

Para minimizar os efeitos negativos da adoção de dessecantes, alternativas têm sido apresentadas, dentre elas o uso de caldas concentradas em nitrogênio para dessecação de plantas daninhas e da cobertura vegetal. Essa alternativa não inclui a aplicação de herbicidas e o nitrogênio empregado para a dessecação pode ser aproveitado pela cultura de interesse. Sabidamente, elevadas concentrações foliares de amônio podem provocar danos às estruturas das plantas (Devine et al., 1993; Hopkins, 1995); contudo, não foram encontrados trabalhos científicos que justifiquem a aplicação de nitrogênio com essa finalidade. Por essa razão, este trabalho foi desenvolvido com o objetivo de avaliar diferentes aspectos da participação do nitrogênio na indução de injúrias foliares e na eficácia do herbicida glyphosate.

\section{MATERIAL E MÉTODOS}

Três experimentos foram desenvolvidos no município de Piracicaba, Estado de São Paulo (22 $42^{\prime}$ 30" Latitude Sul, 47³8' 00" Longitude Oeste e $546 \mathrm{~m}$ de altitude), sendo dois em casa de vegetação e um em campo. Para a condição de casa de vegetação, utilizou-se estrutura do Departamento de Produção Vegetal, da Escola Superior de Agricultura "Luiz de Queiroz" (Esalq/USP). Nesse ambiente, os experimentos foram instalados em blocos ao acaso, em que cada parcela constou de um vaso plástico com capacidade para $0,5 \mathrm{~L}$, preenchido com mistura de substrato comercial e vermiculita, na proporção de 2:1, fertilizado com $200 \mathrm{mg}$ de $\mathrm{N}, \mathrm{P}_{2} \mathrm{O}_{5}$ e $\mathrm{K}_{2} \mathrm{O}$.

O primeiro experimento, em casa de vegetação, foi desenvolvido entre maio e agosto de 2008, com o objetivo de comparar o efeito tóxico de caldas concentradas em nitrogênio com os herbicidas comumente recomendados para a condição de dessecação. Para tanto, a aveia-preta (Avena strigosa Schreb) foi utilizada como bioindicador, distribuindo-se três sementes por parcela. Após emergência, as parcelas foram desbastadas, mantendo-se densidade uniforme de duas plantas por vaso. Por ocasião da aplicação dos tratamentos, constatou-se estádio fenológico de 3 - 4 folhas e 2 - 3 perfilhos.

Nesse experimento, foram utilizados sete tratamentos com cinco repetições. Os tratamentos aplicados foram: glyphosate, a $1440 \mathrm{~g} \mathrm{ha}^{-1}$ (Roundup Original ${ }^{\circledR}$ ), paraquat, a $400 \mathrm{~g} \mathrm{ha}^{-1}$ (Gramoxone 200 ${ }^{\circledR}$ ), glufosinato de amônio, a $200 \mathrm{~g}$ ha $^{-1}\left(\right.$ Finale $\left.^{\circledR}\right)$, caldas concentradas com 10, 15 e $20 \%$ de nitrogênio, além da testemunha, sem aplicação. Em todos os trabalhos, para obtenção das caldas sem herbicida e com elevada concentração de nitrogênio, foi utilizado fertilizante fluido comercial Uran (32-00-00), que é resultado da mistura de nitrato de amônio $(44,3 \%)$ com ureia $(35,4 \%)$ e contém $14 \%$ de $\mathrm{NH}_{2}^{-}, 9 \%$ de $\mathrm{NH}_{4}^{+}$e $9 \%$ de $\mathrm{NO}_{3}^{-}$.

$\mathrm{O}$ segundo experimento, em casa de vegetação, foi desenvolvido entre outubro e dezembro de 2008, com o objetivo de avaliar a eficácia do herbicida glyphosate, quando pulverizado com solução de fertilizantes nitrogenados. Os tratamentos foram consequência da combinação fatorial entre duas espécies de plantas daninhas e 
seis níveis do fator herbicida, com seis repetições. As plantas daninhas estudadas foram: corda-de-viola (Ipomoea triloba L.) e capim-massambará (Sorghum halepense (L.) Pers.). Com relação à corda-de-viola, foram mantidas quatro plantas por vaso e a aplicação foi realizada quando se constatou estádio fenológico de cinco folhas definitivas. No caso do capim-massambará, mantiveram-se três plântulas por vaso e a aplicação foi realizada sobre plantas com quatro folhas e sem perfilhos.

Os tratamentos estão detalhadamente descritos na Tabela 1, sendo fundamentados na pulverização de glyphosate (Roundup Original ${ }^{\circledR}$ ), utilizando-se os seguintes veículos: água, solução de sulfato de amônio - SA (15 $\left.\mathrm{g} \mathrm{L}^{-1}\right)$, solução de ureia - U $\left(5 \mathrm{~g} \mathrm{~L}^{-1}\right)$ ou solução de $\mathrm{U}+\mathrm{SA}$ $\left(2,5+7,5 \mathrm{~g} \mathrm{~L}^{-1}\right)$. Os fertilizantes nitrogenados adicionados à calda de glyphosate foram provenientes de fontes convencionais utilizadas nas adubações agrícolas, com concentrações de 21 e $45 \%$ de $\mathrm{N}$ no sulfato de amônio e ureia, respectivamente.

O terceiro experimento foi desenvolvido em área do Departamento de Produção Vegetal da Esalq/USP, entre março e abril de 2009. O trabalho foi instalado em área de aterro com cerca de $2,5 \mathrm{~m}$ de altura, relevo plano, solo de textura média-argilosa, $\mathrm{pH} 4,5$, com 2,1\% de matéria orgânica e $39 \%$ de saturação por bases. Constatou-se infestação de capim-braquiária (Brachiaria decumbens Stapf), considerada como espécie dominante (96\%), cuja densidade foi estimada em 180 perfilhos $\mathrm{m}^{-2}$.
Em campo, também foi utilizado delineamento de blocos ao acaso, com seis tratamentos e seis repetições. As parcelas contaram com as dimensões de 3 x 4 m e área útil de 7,5 $\mathrm{m}^{2}$. Os tratamentos estão detalhadamente descritos na Tabela 1, incluindo aplicações de glyphosate isolado, glyphosate após fertilização da área com sulfato de amônio, distribuído a lanço sobre o solo, glyphosate combinado com adição de sulfato de amônio à calda de pulverização, ou uso de somente calda concentrada com $20 \%$ de nitrogênio. No momento da aplicação dos tratamentos, registrou-se estádio fenológico de florescimento/ frutificação para o capim-braquiária.

Para os experimentos desenvolvidos em casa de vegetação, as aplicações foram realizadas em câmara de pulverização pressurizada por ar comprimido, equipada com uma única ponta do tipo jato plano, modelo XR 80.02, a 0,50 $\mathrm{m}$ da superfície do alvo, calibrada para volume de calda proporcional a $200 \mathrm{~L} \mathrm{ha}^{-1}$. Após a pulverização, os vasos permaneceram sem irrigação por 24 horas, visando a assegurar a completa absorção dos herbicidas. Em todos os experimentos, a água utilizada no preparo das caldas e soluções foi oriunda de tratamento comum para distribuição pública, realizado na própria Esalq/USP, cuja análise está apresentada na Tabela 2.

Para as aplicações em campo, utilizou-se pulverizador costal pressurizado por $\mathrm{CO}_{2}$, acoplado a uma barra de pulverização com largura total de $2 \mathrm{~m}$, com quatro pontas do tipo jato plano, modelo XR 110.02, espaçadas

Tabela 1. Tratamentos aplicados no segundo (Ipomoea triloba e Sorghum halepense) e terceiro (Brachiaria decumbens) experimentos

\begin{tabular}{|c|c|c|c|c|c|}
\hline \multicolumn{6}{|c|}{ Segundo Experimento } \\
\hline \multicolumn{3}{|c|}{ Tratamento } & \multicolumn{3}{|l|}{ Fertilizante Nitrogenado } \\
\hline \multirow{2}{*}{$\mathbf{N}^{\circ}$} & \multirow{2}{*}{ Condição } & \multirow{2}{*}{$\frac{\text { Dose }}{\left(\text { g ha }^{-1}\right)}$} & \multirow{2}{*}{ Fonte } & \multicolumn{2}{|c|}{$\operatorname{Dose}^{2}$} \\
\hline & & & & $\left(g^{-1}\right)$ & $\left(\mathrm{kg} \mathrm{ha}^{-1}\right)$ \\
\hline 1 & \multicolumn{2}{|c|}{ Testemunha sem aplicação } & Ausente & 0,0 & 0,0 \\
\hline 2 & Glyphosate $^{1}$ & 360 & Ausente & 0,0 & 0,0 \\
\hline 3 & Glyphosate & 360 & Sulfato de Amônio & 15,0 & 3,0 \\
\hline 4 & Glyphosate & 360 & Ureia & 5,0 & 1,0 \\
\hline 5 & Glyphosate & 360 & Ureia + Sulfato de Amônio & $2,5+7,5$ & $0,5+1,5$ \\
\hline 6 & Glyphosate & 720 & Ausente & 0,0 & 0,0 \\
\hline \multicolumn{6}{|c|}{ Terceiro Experimento } \\
\hline \multicolumn{3}{|c|}{ Tratamento } & \multicolumn{3}{|l|}{\begin{tabular}{|c|} 
Fertilizante Nitrogenado \\
\end{tabular}} \\
\hline \multirow{2}{*}{$\mathbf{N}^{\circ}$} & \multirow{2}{*}{ Condição } & Dose & \multirow{2}{*}{ Fonte } & \multicolumn{2}{|c|}{ Dose $^{2}$} \\
\hline & & $\left(\mathrm{g} \mathrm{ha}^{-1}\right)$ & & $\left(g^{-1}\right)$ & $\left(\mathrm{kg} \mathrm{ha}^{-1}\right)$ \\
\hline 1 & \multicolumn{2}{|c|}{ Testemunha sem aplicação } & Ausente & 0,0 & 0,0 \\
\hline 2 & Glyphosate $^{1}$ & 1080 & Ausente & 0,0 & 0,0 \\
\hline 3 & Glyphosate & 1080 & Fertilização prévia do solo com Sulfato de Amônio & - & 150,0 \\
\hline 4 & Glyphosate & 1080 & Sulfato de Amônio dissolvido na calda & 15,0 & 3,0 \\
\hline 5 & Ausente & - & Calda concentrada com $20 \%$ de nitrogênio & 200,0 & 40,0 \\
\hline 6 & Glyphosate & 1800 & Ausente & 0,0 & 0,0 \\
\hline
\end{tabular}

${ }^{1}$ Roundup Original ${ }^{\oplus}, 360$ g e.a. $\mathrm{L}^{-1} ;{ }^{2}$ Volume de calda proporcional a $200 \mathrm{~L} \mathrm{ha}^{-1}$. 
em $0,50 \mathrm{~m}$, também calibrado para volume de calda proporcional a $200 \mathrm{~L} \mathrm{ha}^{-1}$. Neste experimento, a aplicação foi realizada no dia 16/03/2009, das 8:20 às 8:50 h. No momento da pulverização, os parâmetros meteorológicos médios foram: umidade relativa de $97 \%$, temperatura do ar de $22^{\circ} \mathrm{C}$, ausência de nuvens e ventos de $1,4 \mathrm{~km} \mathrm{~h}^{-1}$. A primeira chuva foi registrada em período superior a 72 horas após aplicação. As precipitações e a temperatura média diária do período em que o experimento esteve em campo estão apresentadas na Figura 1. Em razão da proposta experimental, as parcelas do Tratamento 3 (Tabela 1) foram fertilizadas com sulfato de amônio seis dias antes da aplicação do herbicida (10/03/2009), distribuindose o fertilizante a lanço $\left(150 \mathrm{~kg} \mathrm{ha}^{-1}\right)$.

As variáveis avaliadas foram: controle percentual aos 14, 21 e 28 dias após a aplicação (DAA) e massa de matéria seca residual aos $28 \mathrm{DAA}$. Apenas no primeiro experimento desenvolvido em casa de vegetação, as avaliações de controle foram realizadas até os 42 DAA, quando, então, foi medida a massa de matéria seca. Para as avaliações de controle, utilizou-se escala visual, com variação entre zero e $100 \%$, em que zero representou a ausência de sintomas e 100 a morte de todas as plantas. Em casa de

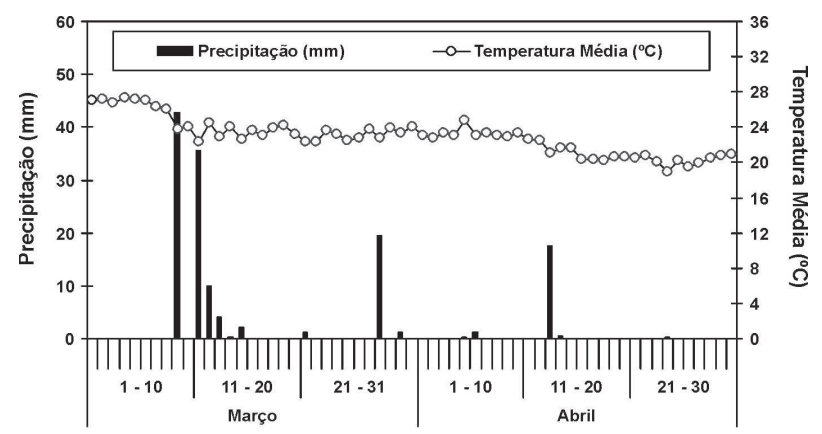

Meses / Dias (2009)

Figura 1. Temperatura média e precipitações diárias observadas durante o período de desenvolvimento do experimento em campo, no município de Piracicaba, São Paulo. vegetação, para a mensuração da massa de matéria seca, cortaram-se as plantas de cada parcela rente à superfície do substrato e todo o material foi secado em estufa (70 ${ }^{\circ} \mathrm{C}$ ), por 72 horas. Para o segundo experimento em casa de vegetação, visando à comparação entre as plantas daninhas, a massa de matéria seca residual foi transformada em escala percentual, considerando-se $100 \%$ a massa das parcelas sem aplicação de cada bloco. Em campo, um quadro de ferro de 0,5 x 0,5 m foi lançado uma vez em área representativa de cada parcela. Todo o material vegetal presente na área do quadrado foi cortado rente ao solo e secado em estufa.

Todos os dados foram submetidos à aplicação do teste F na análise da variância. Quando foram identificados efeitos significativos, utilizou-se teste de agrupamento de médias de Scott-Knott (Scott \& Knott, 1974) para análise dos níveis de tratamentos. No segundo experimento em casa de vegetação, aplicou-se teste t para comparação das espécies. Todos os testes foram adotados, considerando-se níveis mínimos de 5\% de significância.

\section{RESULTADOS E DISCUSSÃO}

O controle percentual da aveia-preta, bem como a massa de matéria seca residual observada após aplicação dos tratamentos experimentais, está apresentado na Tabela 3. Aos 14 DAA, os melhores resultados de dessecação foram obtidos com aplicação de paraquat ou glufosinato de amônio, alcançando controles superiores a 99\%. O glyphosate, por sua vez, teve ação inicial mais lenta, igualando-se aos demais herbicidas aos 21 DAA, com morte de todas as plantas aos 42 DAA. Na última avaliação de controle, aos 42 DAA, observou-se início de rebrote da aveia preta no tratamento com paraquat, que não foi suficiente porém, para diferenciá-lo dos demais tratamentos (Tabela 3).

Nas células, a molécula de glyphosate inibe a EPSPs (enol piruvil shiquimato fosfato sintase), enzima

Tabela 2. Análise da água utilizada nas aplicações, submetida a tratamento usual para distribuição pública

\begin{tabular}{|c|c|c|c|c|c|}
\hline Parâmetro & Unidade & Resultado & Parâmetro & Unidade & Resultado \\
\hline Cloreto $\left(\mathrm{Cl}^{-}\right)$ & $m g \mathrm{~L}^{-1}$ & 43,6 & Zinco $(\mathrm{Zn})$ & $\operatorname{mg~L}{ }^{-1}$ & 0,04 \\
\hline Nitrato $\left(\mathrm{N}-\mathrm{NO}_{3}^{-}\right)$ & $\operatorname{mg~L} \mathrm{L}^{-1}$ & 4,0 & Alcalinidade $\left(2 \mathrm{CO}_{3}^{2-}+\mathrm{HCO}_{3}^{-}\right)$ & $\operatorname{mg~L} \mathrm{L}^{-1}$ & 49,6 \\
\hline Sulfato $\left(\mathrm{SO}_{4}^{2-}\right)$ & $m g L^{-1}$ & 33,0 & Nitrogênio Amoniacal $\left(\mathrm{N}-\mathrm{NH}_{3}\right)$ & $\operatorname{mg~L} \mathrm{L}^{-1}$ & 0,2 \\
\hline Fósforo $(\mathrm{P})$ & $\operatorname{mg~L}{ }^{-1}$ & 0,02 & Cor Aparente & PtCo & 0,0 \\
\hline Sódio $\left(\mathrm{Na}^{+}\right)$ & $m g L^{-1}$ & 66,0 & Turbidez & FTU & 0,0 \\
\hline Potássio $\left(\mathrm{K}^{+}\right)$ & $m g L^{-1}$ & 5,6 & Sedimentos em suspensão & $m g L^{-1}$ & 4,3 \\
\hline Cálcio $\left(\mathrm{Ca}^{2+}\right)$ & $\mathrm{mg} \mathrm{L}^{-1}$ & 31,8 & Condutividade elétrica (CE) & $\mathrm{mS} \mathrm{cm}{ }^{-1}$ & 0,33 \\
\hline Magnésio $\left(\mathrm{Mg}^{2+}\right)$ & $m g L^{-1}$ & 2,8 & $\mathrm{pH}$ & - & 7,5 \\
\hline Ferro $(\mathrm{Fe})$ & $m g L^{-1}$ & 0,0 & Gás Carbônico $\left(\mathrm{CO}_{2}\right)$ & $\operatorname{mg~L} L^{-1}$ & 2,5 \\
\hline Cobre $(\mathrm{Cu})$ & $m g \mathrm{~L}^{-1}$ & 0,0 & Acidez $\left(\mathrm{CaCO}_{3}\right)$ & $\operatorname{mg~L}{ }^{-1}$ & 5,0 \\
\hline Manganês (Mn) & $m g L^{-1}$ & 0,01 & Dureza Total* $\left(\mathrm{CaCO}_{3}\right)$ & $\operatorname{mg~L} \mathrm{L}^{-1}$ & 91,0 \\
\hline
\end{tabular}

Análises realizadas pelo Laboratório de Ecologia Aplicada, Departamento de Ciências Florestais, Esalq/USP. *Dureza Total, calculada com base no equivalente de Carbonato de Cálcio $\left(\mathrm{CaCO}_{3}\right)$, segundo Franson (1995): 2,497 [Ca, mg L-1] + 4,118 [Mg, $\left.\mathrm{mg} \mathrm{L}^{-1}\right]$. 
que participa da rota de síntese dos aminoácidos aromáticos fenilalanina, tirosina e triptofano (Cole, 1985). Os sintomas resultantes da aplicação do glyphosate são lentos, iniciando-se pelo amarelecimento progressivo das folhas, murchamento com posterior necrose e morte das plantas, e podem demorar de 4 a 20 dias, conforme a espécie e estádio fenológico (Rodrigues \& Almeida, 2005).

Com relação à pulverização de caldas concentradas em nitrogênio sobre a aveia-preta, os maiores danos foliares foram observados aos 28 DAA, da ordem de $30 \%$ e sem diferença entre as soluções. Nesses tratamentos, foram observadas necroses foliares e redução no crescimento, esses danos não foram, porém, suficientes para promover a morte das plantas. Ao término do experimento, a mensuração da massa de matéria seca de aveia-preta validou as análises visuais de controle, em que maiores reduções foram observadas para aplicação dos herbicidas. A testemunha, sem aplicação, acumulou mais massa, enquanto as plantas submetidas às caldas concentradas em nitrogênio mantiveram-se em condição intermediária (Tabela 3$)$.

Uma das hipóteses, que explica os danos foliares causados pela pulverização de caldas concentradas em nitrogênio, está relacionada com a elevada concentração de amônio nas células. Segundo Malavolta (1980) e Silva \& Stutte (1981), a intoxicação por amônio nos tecidos foliares ocorre quando o íon acumula-se em velocidade superior aos processos de metabolização. Ainda, além das fontes amoniacais, as caldas concentradas em nitrogênio que utilizam Uran para seu preparo também possuem moléculas de nitrato. Nas plantas, o nitrato não participa de compostos orgânicos e, para ser útil aos vegetais, é reduzido a amônio, pela ação das enzimas nitrato redutase e nitrito redutase (Hopkins, 1995; Sodek, 2004).
O acúmulo de amônio promove o bloqueio da fotossíntese, interfere na síntese de ATP, durante a série de transporte eletrônico nas mitocôndrias e cloroplastos, e provoca, ainda, a ruptura da estrutura dos cloroplastos. A energia de excitação da clorofila pode ser então convertida à redução do oxigênio molecular, nitrito, enxofre e fósforo e, ainda, na formação de clorofila 'triplet' (Devine et al., 1993; Hopkins, 1995). Por outro lado, por sua natureza tóxica, o amônio é rapidamente assimilado em compostos orgânicos (amidas e aminoácidos), o que reduz as chances de intoxicação do vegetal, uma vez que a eficiência desse processo é muito superior à taxa de redução do $\mathrm{NO}_{3}{ }^{-}$(Nielsen \& Schjoerring, 1998; Sodek, 2004; Damin et al., 2008). Assim sendo, neste trabalho, supõe-se que as plantas de aveia-preta foram capazes de metabolizar ou isolar rapidamente o excesso de amônio, minimizando os danos foliares decorrentes desta aplicação (Tabela 3).

Fertilizantes nitrogenados também têm sido utilizados, visando a elevar a eficácia de herbicidas, sobretudo por meio de sua dissolução na calda de pulverização (Thelen et al., 1995; Young et al., 2003; Nurse et al., 2008). No segundo experimento, para todas as avaliações, a adição de sulfato de amônio à calda do glyphosate elevou o controle da corda-de-viola, igualando a eficácia da menor dose do herbicida $\left(360 \mathrm{~g} \mathrm{ha}^{-1}\right)$ à da maior dose aplicada (720 g $\left.\mathrm{ha}^{-1}\right)$. Nas avaliações de controle, realizadas aos 14 e 21 DAA, e para massa de matéria seca da parte aérea, a aplicação de glyphosate com solução de U+SA também resultou em igualdade de eficácia à aplicação isolada da maior dose (Tabela 4).

Em geral, nenhum tratamento herbicida controlou satisfatoriamente a corda-de-viola, com níveis sempre inferiores a $80 \%$, que é a percentagem mínima para que um tratamento herbicida seja considerado adequado (Frans et al., 1986). Nas mesmas avaliações, o capim-massambará

Tabela 3. Controle percentual de aveia-preta (Avena strigosa), avaliado aos 14, 21, 28 e 42 dias após aplicação (DAA) dos tratamentos e massa de matéria seca avaliada aos 42 DAA

\begin{tabular}{|c|c|c|c|c|c|}
\hline \multirow[t]{2}{*}{$\begin{array}{l}\text { Tratamento } \\
\left(\mathrm{g} \mathrm{ha}^{-1}\right)\end{array}$} & \multicolumn{4}{|c|}{$\begin{array}{c}\text { Controle Percentual* } \\
\text { (DAA) }\end{array}$} & \multirow{2}{*}{$\begin{array}{l}\text { Massa de } \\
\text { Matéria } \\
\text { Seca* } \\
\left(\text { g parcela-1) }^{-1}\right)\end{array}$} \\
\hline & 14 & 21 & 28 & 42 & \\
\hline Testemunha sem aplicação & $0,0 \mathrm{E}$ & $0,0 \mathrm{D}$ & $0,0 \mathrm{C}$ & $0,0 \mathrm{C}$ & $9,1 \mathrm{C}$ \\
\hline Glyphosate a 1440 & $80,0 \mathrm{~B}$ & $95,4 \mathrm{~A}$ & $99,0 \mathrm{~A}$ & $100,0 \mathrm{~A}$ & $1,8 \mathrm{~A}$ \\
\hline Paraquat $^{1}$ a 400 & $99,2 \mathrm{~A}$ & $99,4 \mathrm{~A}$ & $99,2 \mathrm{~A}$ & $97,6 \mathrm{~A}$ & $0,8 \mathrm{~A}$ \\
\hline Glufosinato de Amônio² a 400 & $99,4 \mathrm{~A}$ & $100,0 \mathrm{~A}$ & $100,0 \mathrm{~A}$ & $100,0 \mathrm{~A}$ & $1,1 \mathrm{~A}$ \\
\hline Nitrogênio a $10 \%$ & $6,0 \mathrm{D}$ & $12,4 \mathrm{C}$ & $27,0 \mathrm{~B}$ & $27,0 \mathrm{~B}$ & $6,6 \mathrm{~B}$ \\
\hline Nitrogênio a $15 \%$ & $6,0 \mathrm{D}$ & $16,0 \mathrm{C}$ & $30,0 \mathrm{~B}$ & $26,0 \mathrm{~B}$ & $7,8 \mathrm{~B}$ \\
\hline Nitrogênio a $20 \%$ & $20,0 \mathrm{C}$ & $21,0 \mathrm{~B}$ & $30,0 \mathrm{~B}$ & $26,0 \mathrm{~B}$ & $6,5 \mathrm{~B}$ \\
\hline $\mathrm{F}_{\text {(trat) }}$ & $594,53 * *$ & $425,75^{* *}$ & $163,28 * *$ & $119,02 * *$ & $34,12 * *$ \\
\hline $\mathrm{CV}(\%)$ & 9,55 & 10,22 & 13,60 & 16,57 & 27,42 \\
\hline
\end{tabular}

${ }^{1}$ Adição de Agral a $0,5 \% ;{ }^{2}$ Adição de Hoefix a $0,5 \%$; *Médias seguidas por letras iguais, na coluna, não diferem entre si segundo teste de Scott-Knott, com $5 \%$ de significância; **Teste F significativo a $1 \%$. 
foi a espécie mais susceptível ao produto (Tabela 4), exceto na análise de massa de matéria seca, em que a igualdade entre as espécies foi obtida com a pulverização de glyphosate a $720 \mathrm{~g} \mathrm{ha}^{-1}$ ou com a menor dose $\left(360 \mathrm{~g} \mathrm{ha}^{-1}\right)$, utilizando-se solução de SA e de U+SA como veículo de pulverização. Em concordância com Carvalho et al. (2009a), a pulverização de glyphosate com soluções nitrogenadas apenas acelerou a morte do capimmassambará, sem constatação de diferença na avaliação de controle e massa de matéria seca, realizada aos 28 DAA (Tabela 4).

Conforme discutido por Carvalho et al. (2009b; 2010), quando da utilização de água com baixa concentração de sais (Tabela 2), as principais atividades benéficas decorrentes da adição de sulfato de amônio à calda são: a formação de sais glyphosate-amônio que possuem maior facilidade de absorção (Nalewaja et al., 1992; Thelen et al., 1995); alteração na morfologia das gotas, atrasando ou prevenindo a cristalização do glyphosate na superfície foliar (MacIsaac et al., 1991); a acidificação do apoplasto foliar, que facilita a absorção celular de herbicidas ácido fracos (Gronwald et al., 1993; Ruiter \& Meinen, 1996; Young et al., 2003). O principal mecanismo relatado para a ureia diz respeito à contribuição na penetração cuticular, por rompimento de ligações éster, éter e di-éter da cutina e difusão facilitada desta molécula (Durigan, 1992; Witte et al., 2002).

Em campo, aos 14 e 21 DAA, o tratamento que promoveu o melhor controle do capim-braquiária foi a aplicação de $1800 \mathrm{~g} \mathrm{ha}^{-1}$ de glyphosate (Tabela 5). Por outro lado, em concordância com os dados de aveia-preta, a aplicação de caldas concentradas em nitrogênio não alcançou adequada dessecação das plantas, com danos máximos da ordem de $16 \%$. Após pulverização desse tratamento, foram observados pontos necróticos nos limbos, derriça de sementes, bem como dessecação da ponta de algumas folhas. Contudo, ao término do experimento, foram identificadas diferenças visuais na coloração das plantas, em que as tratadas estiveram mais verdes que a testemunha, sem aplicação.

Os tratamentos fundamentados na menor dose de glyphosate não foram diferentes entre si, aos 14 DAA, ou

Tabela 4. Controle percentual da corda-de-viola (Ipomoea triloba - IPOTR) e do capim-massambará (Sorghum halepense - SORHA), avaliado aos 14, 21 e 28 dias após aplicação (DAA) dos tratamentos e massa de matéria seca residual

\begin{tabular}{|c|c|c|c|c|c|c|}
\hline \multirow{3}{*}{ Tratamentos } & \multicolumn{2}{|c|}{ Doses } & \multicolumn{4}{|c|}{ Controle Percentual* } \\
\hline & \multirow{2}{*}{$\begin{array}{c}\text { Herbicida } \\
\text { g ha }^{-1}\end{array}$} & \multirow{2}{*}{$\begin{array}{l}\mathrm{FN}^{2} \\
\mathrm{~g} \mathbf{L}^{-1}\end{array}$} & \multicolumn{2}{|c|}{14 DAA } & \multicolumn{2}{|c|}{21 DAA } \\
\hline & & & IPOTR & SORHA & IPOTR & SORHA \\
\hline Testemunha sem aplicação & - & - & $0,0 \mathrm{C} \mathrm{a}$ & $0,0 \mathrm{C} \mathrm{a}$ & $0,0 \mathrm{C} \mathrm{a}$ & $0,0 \mathrm{C} \mathrm{a}$ \\
\hline Glyphosate & 360 & - & $36,7 \mathrm{~B} \mathrm{~b}$ & $55,0 \mathrm{~B} \mathrm{a}$ & $38,3 \mathrm{~B} \mathrm{~b}$ & $83,2 \mathrm{~B} \mathrm{a}$ \\
\hline Glyphosate + SA $^{1}$ & 360 & 15,0 & $49,2 \mathrm{~A} \mathrm{~b}$ & $79,8 \mathrm{~A} \mathrm{a}$ & $55,0 \mathrm{~A} \mathrm{~b}$ & $90,5 \mathrm{~B} \mathrm{a}$ \\
\hline Glyphosate + Ureia (U) & 360 & 5,0 & $41,8 \mathrm{~B} \mathrm{~b}$ & $89,8 \mathrm{~A} \mathrm{a}$ & $30,8 \mathrm{~B} \mathrm{~b}$ & $97,2 \mathrm{~A} \mathrm{a}$ \\
\hline Glyphosate + U + SA & 360 & $2,5+7,5$ & $54,2 \mathrm{~A} \mathrm{~b}$ & $84,0 \mathrm{~A} \mathrm{a}$ & $51,7 \mathrm{~A} \mathrm{~b}$ & $97,7 \mathrm{~A} \mathrm{a}$ \\
\hline Glyphosate & 720 & - & $52,0 \mathrm{~A} \mathrm{~b}$ & $84,2 \mathrm{~A} \mathrm{a}$ & $56,2 \mathrm{Ab}$ & $97,0 \mathrm{~A} \mathrm{a}$ \\
\hline $\mathrm{F}_{\text {(Trat x Exp) }}$ & $5,55^{* *}$ & $20,25^{* *}$ & & & & \\
\hline DMS- ${ }_{\text {Espécies }}$ & 13,67 & 9,69 & & & & \\
\hline $\mathrm{CV}(\%)$ & 22,63 & 14,41 & & & & \\
\hline \multirow[t]{2}{*}{ Tratamentos } & & & \multicolumn{2}{|c|}{28 DAA } & \multicolumn{2}{|c|}{$\begin{array}{c}\text { Massa de Matéria } \\
\operatorname{Seca}^{3}(\%)\end{array}$} \\
\hline & & & IPOTR & SORHA & IPOTR & SORHA \\
\hline Testemunha sem aplicação & - & - & $0,0 \mathrm{D} \mathrm{a}$ & $0,0 \mathrm{~B} \mathrm{a}$ & $100,0 \mathrm{~B} \mathrm{a}$ & $100,0 \mathrm{~B} \mathrm{a}$ \\
\hline Glyphosate & 360 & - & $27,5 \mathrm{C} \mathrm{b}$ & $98,5 \mathrm{~A} \mathrm{a}$ & $103,3 \mathrm{~B} \mathrm{~b}$ & $47,7 \mathrm{~A} \mathrm{a}$ \\
\hline Glyphosate + SA $^{1}$ & 360 & 15,0 & $61,7 \mathrm{~A} \mathrm{~b}$ & $98,8 \mathrm{~A} \mathrm{a}$ & $57,2 \mathrm{~A} \mathrm{a}$ & $51,0 \mathrm{~A} \mathrm{a}$ \\
\hline Glyphosate + Ureia (U) & 360 & 5,0 & $25,8 \mathrm{C} \mathrm{b}$ & $99,2 \mathrm{~A} \mathrm{a}$ & $119,7 \mathrm{~B} \mathrm{~b}$ & $42,7 \mathrm{~A} \mathrm{a}$ \\
\hline Glyphosate + U + SA & 360 & $2,5+7,5$ & $46,7 \mathrm{~B} \mathrm{~b}$ & $99,5 \mathrm{~A} \mathrm{a}$ & $62,9 \mathrm{~A} \mathrm{a}$ & $36,6 \mathrm{~A} \mathrm{a}$ \\
\hline Glyphosate & 720 & - & $55,8 \mathrm{Ab}$ & $98,7 \mathrm{~A} \mathrm{a}$ & $72,9 \mathrm{~A} \mathrm{a}$ & $48,1 \mathrm{~A} \mathrm{a}$ \\
\hline$\overline{\mathrm{F}_{(\operatorname{Trat} \mathrm{Fxp})}}$ & $41,31 * *$ & $3,12^{*}$ & & & & \\
\hline $\begin{array}{l}\text { (Irat x Exp) } \\
\text { DMS }_{\text {Espécies }}\end{array}$ & 8,39 & - & & & & \\
\hline $\mathrm{CV}(\%)$ & 12,22 & 19,52 & & & & \\
\hline
\end{tabular}

${ }^{1} \mathrm{SA}$ - Sulfato de Amônio; ${ }^{2} \mathrm{FN}$ - Fontes Nitrogenadas; ${ }^{3}$ Dados originais apresentados, porém previamente transformados por $\sqrt{x+0,5}$; Para cada variável, médias seguidas por letras iguais, maiúsculas nas colunas e minúsculas nas linhas, não diferem entre si segundo teste de agrupamento de médias de Scott-Knott (coluna) ou teste 't' (linha), com 5\% de significância; *Teste F significativo a 5\%; ** Teste F significativo a $1 \%$. 
seja, não foram observados efeitos das fontes nitrogenadas nesta avaliação. Aos 21 DAA, no tratamento que envolveu fertilização prévia do solo com sulfato de amônio, observou-se maior controle da espécie vegetal, quando comparado com os demais, que utilizaram a mesma dose e, aos 28 DAA, esse tratamento teve controle igual ao obtido com a aplicação isolada da maior dose de glyphosate (Tabela 5).

Neste sentido, Cathcart et al. (2004) observaram que a disponibilidade de nitrogênio às plantas interferiu no controle de algumas espécies daninhas (Setaria viridis (L.) P. Beauv. e Amaranthus retroflexus L.), em que plantas com maior disponibilidade de nitrogênio foram controladas mais facilmente pelos herbicidas. Também Dickson et al. (1990) reportaram que plantas de Avena sativa L. foram mais tolerantes ao fluazifop e ao glyphosate, quando se desenvolveram em ambiente com menor disponibilidade de nitrogênio.

Os mecanismos responsáveis pela maior eficácia de herbicidas aplicados sobre plantas com maior disponibilidade de nitrogênio ainda não estão bem esclarecidos; contudo, supõe-se que a maior atividade metabólica presente nestas plantas contribua para a melhor ação dos produtos. No caso do glyphosate, é sabido que a translocação representa um processo de grande importância para sua eficácia (Wanamarta \& Penner, 1989). O movimento do glyphosate no floema das plantas segue a mesma rota dos produtos da fotossíntese, ocorrendo, das folhas fotossinteticamente ativas (fontes), em direção às partes do vegetal que utilizam esses açúcares (drenos) (Caseley \& Coupland, 1985; Monquero et al., 2004). Assim sendo, condições que favoreçam a fotossíntese também auxiliam a translocação do glyphosate (Della-Cioppa et al., 1986), contribuindo para a maior eficácia do produto.
Vale ressaltar, ainda, que a aplicação de sulfato de amônio via solo foi realizada apenas seis dias antes da pulverização do glyphosate e que as condições meteorológicas foram favoráveis à dissolução do produto, com ocorrência de chuvas nos dias que sucederam a fertilização (Figura 1). Neste sentido, considerando-se o melhor controle obtido por este tratamento, quando comparado com o tratamento com somente glyphosate na mesma dose (Tabela 5), supõe-se que houve tempo suficiente para absorção e transporte do nitrogênio pelas plantas. Neste caso, outra hipótese viável a maior eficácia do glyphosate neste tratamento diz respeito à acidificação do apoplasto foliar, após metabolização celular do amônio, o que facilita a absorção do glyphosate, de forma similar ao que ocorre quando da aplicação deste fertilizante via calda herbicida (Gronwald et al., 1993; Ruiter \& Meinen, 1996).

$\mathrm{Na}$ análise da massa de matéria seca do capimbraquiária, todos os tratamentos que envolveram aplicações de glyphosate foram iguais entre si, diferenciandose da testemunha sem aplicação e das plantas tratadas com calda concentrada em nitrogênio. Ainda, para nenhuma variável, a aplicação de glyphosate, utilizando-se solução de sulfato de amônio como veículo, resultou em controles superiores à aplicação isolada da mesma dose do produto (Tabela 5). Essas observações indicam diferenças na resposta de espécies de plantas daninhas à pulverização de glyphosate com fertilizantes nitrogenados, ou, também, sugerem necessidade de maior concentração de sulfato de amônio na calda, para aplicação em capimbraquiária, uma vez que sua administração via solo foi eficiente para maior controle. Ainda, em todos os experimentos, não houve evidências de que a maior eficácia do herbicida glyphosate, observada após adição de fertilizantes nitrogenados à calda ou ao solo, esteja relacionada com a toxicidade direta do íon amônio.

Tabela 5. Controle percentual de capim-braquiária (Braquiaria decumbens) aos 14, 21 e 28 dias após aplicação (DAA) dos tratamentos e massa de matéria seca residual aos 28 DAA

\begin{tabular}{|c|c|c|c|c|}
\hline \multirow{2}{*}{ Tratamentos } & \multicolumn{3}{|c|}{ Controle Percentual* } & \multirow{2}{*}{$\begin{array}{c}\text { Massa de } \\
\text { Matéria } \\
\text { Seca* } \\
\left(\mathrm{g} \mathrm{m}^{-2}\right)\end{array}$} \\
\hline & 14 DAA & 21 DAA & 28 DAA & \\
\hline Testemunha sem Aplicação & $0,0 \mathrm{D}$ & $0,0 \mathrm{E}$ & $0,0 \mathrm{D}$ & $696,9 \mathrm{~B}$ \\
\hline Glyphosate a $1080 \mathrm{~g} \mathrm{ha}^{-1}$ & $74,6 \mathrm{~B}$ & $85,3 \mathrm{C}$ & $87,0 \mathrm{~B}$ & $619,5 \mathrm{~A}$ \\
\hline Fertilização Prévia ${ }^{1}$ do Solo com Sulfato de Amônio + Glyphosate a $1080 \mathrm{~g} \mathrm{ha}^{-1}$ & $75,4 \mathrm{~B}$ & $88,8 \mathrm{~B}$ & $91,9 \mathrm{~A}$ & $578,7 \mathrm{~A}$ \\
\hline Glyphosate a $1080 \mathrm{~g} \mathrm{ha}^{-1}+$ Sulfato de Amônio em Calda $\left(15 \mathrm{~g} \mathrm{~L}^{-1}\right)$ & $68,5 \mathrm{~B}$ & $80,0 \mathrm{C}$ & $84,8 \mathrm{~B}$ & $492,7 \mathrm{~A}$ \\
\hline Solução aquosa com $20 \%$ de Nitrogênio & $13,5 \mathrm{C}$ & $13,7 \mathrm{D}$ & $16,5 \mathrm{C}$ & $712,5 \mathrm{~B}$ \\
\hline Glyphosate a $1800 \mathrm{~g} \mathrm{ha}^{-1}$ & $86,0 \mathrm{~A}$ & $95,1 \mathrm{~A}$ & $94,9 \mathrm{~A}$ & $578,2 \mathrm{~A}$ \\
\hline $\mathrm{F}_{\text {(trat) }}$ & $189,49 * *$ & $493,21^{* *}$ & $988,47 * *$ & $4,35 * *$ \\
\hline $\mathrm{CV}(\%)$ & 12,26 & 7,67 & 5,30 & 15,76 \\
\hline
\end{tabular}

${ }^{1}$ Fertilização do solo a lanço com sulfato de amônio $\left(150 \mathrm{~kg} \mathrm{ha}^{-1}\right)$, realizada seis dias antes da pulverização do glyphosate; * Médias seguidas por letras iguais nas colunas não diferem entre si segundo teste de agrupamento e médias de Scott-Knott, com 5\% de significância; ** Teste F significativo a $1 \%$.

Rev. Ceres, Viçosa, v. 58, n.4, p. 516-524, jul/ago, 2011 


\section{CONCLUSÃO}

A pulverização de caldas concentradas com até $20 \%$ de nitrogênio não dessecou adequadamente as espécies vegetais visadas (aveia-preta e capim-braquiária), provocando danos máximos de cerca de 30\%;

A utilização de solução de sulfato de amônio, ou de ureia mais sulfato de amônio, como veículo de pulverização de glyphosate elevou o controle da corda-de-viola;

As soluções nitrogenadas aceleraram a atividade do glyphosate para dessecação do capim-massambará, sem diferenças visíveis aos 28 DAA;

A escolha da dose adequada de glyphosate para dessecação do capim-braquiária foi fundamental para obtenção de elevado controle, sendo que a única alternativa que elevou a eficácia da menor dose do produto foi a fertilização prévia do solo com sulfato de amônio.

\section{AGRADECIMENTOS}

Os autores agradecem ao Conselho Nacional de Desenvolvimento Científico e Tecnológico (CNPq) pela concessão de bolsas.

\section{REFERÊNCIAS}

Argenta G, Silva PRF, Fleck NG, Bortolin CG, Neves R \& Agostinetto D (2001) Efeitos do manejo mecânico e químico da aveia-preta no milho em sucessão e no controle do capim-papuã. Pesquisa Agropecuária Brasileira, 36:851-860.

Carvalho SJP, Dias ACR, Shiomi GM \& Christoffoleti PJ (2010) Adição simultânea de sulfato de amônio e ureia à calda de pulverização do herbicida glyphosate. Planta Daninha, 28:575-584.

Carvalho SJP, Damin V, Dias ACR, Melo MSC, Nicolai M \& Christoffoleti PJ (2009a) Dessecação de plantas daninhas com glyphosate em mistura com ureia ou sulfato de amônio. Planta Daninha, 27:353-361.

Carvalho SJP, Damin V, Dias ACR, Yamasaki GM \& Christoffoleti PJ (2009b) Eficácia e pH de caldas de glifosato após a adição de fertilizantes nitrogenados e utilização de pulverizador pressurizado por $\mathrm{CO}_{2}$. Pesquisa Agropecuária Brasileira, 44:569-575.

Caseley JC \& Coupland D (1985) Environmental and plant factors affecting glyphosate uptake movement and acidity. In: Grossbard E \& Atkinson DA (Ed.) The herbicide glyphosate. London, Butterworths. p.92-123.

Cathcart RJ, Chandler K \& Swanton CJ (2004) Fertilizer nitrogen rate and the response of weeds to herbicides. Weed Science, 52:291-296.

Christoffoleti PJ, Carvalho SJP, López-Ovejero RF, Nicolai M, Hidalgo E \& Silva JE (2007) Conservation of natural resources in Brazilian agriculture: implications on weed biology and management. Crop Protection, 26:383-389.

Cole DJ (1985) Mode of action of glyphosate - a literature analysis. In: Grossbard E \& Atkinson DA (Eds.) The herbicide glyphosate. London, Butterworths. p.48-74.

Constantin J, Machado MH, Cavalieri SD, Oliveira Júnior RS Rios FA \& Roso AC (2008) Influência do glyphosate na dessecação de capim-braquiária e sobre o desenvolvimento inicial da cultura do milho. Planta Daninha, 26:627-636.
Damin V (2009) Transformações do nitrogênio no sistema soloplanta após aplicação de herbicidas. Tese de Doutorado. Escola Superior de Agricultura "Luiz de Queiroz", Piracicaba, 130p.

Damin V, Franco HCJ, Moraes MF, Franco A \& Trivelin PCO (2008) Nitrogen loss in Brachiaria decumbens after application of glyphosate or glufosinate-ammonium. Scientia Agricola, 65:402-407

Della-Cioppa G, Bauer SC, Klein BK, Shah DM, Fraley RT \& Kishore G (1986) Translocation of the precursor of 5enolpyruvylshikimate-3-phosphate synthase into chloroplasts of higher plants in vitro. PNAS, 83:6973-6877.

Devine M, Duke SO \& Fedtke C (1993) Physiology of herbicide action. New Jersey, PTR Prencice Hall. 441p.

Dickson RL, Andrews M, Field RJ \& Dickson EL (1990) Effect of water stress, nitrogen, and gibberelic acid on fluazifol and glyphosate activity on oats (Avena sativa). Weed Science, 38:54-61.

Durigan JC (1992) Efeito de adjuvantes na calda e no estádio de desenvolvimento das plantas, no controle do capim-colonião (Panicum maximum) com glyphosate. Planta Daninha, 10:3944.

Frans RE, Talbert R, Marx D \& Crowley H (1986) Experimental design and techniques for measuring and analyzing plant responses to weed control practices. In: Camper ND (Ed.) Research methods in weed science. $3^{\mathrm{a}}$ ed. Champaign, Southern Weed Science Society. p.29-46.

Franson MAH (1995) Standard methods for the examination of water and wastewater. $19^{\mathrm{a}}$ ed. Washington, American Public Health Association. 1074p.

Gauvrit C (2003) Glyphosate response to calcium, ethoxylated amine surfactant, and ammonium sulfate. Weed Technology, 17:799-804.

Gronwald JW, Jourdan SW, Wyse DL, Somers DA \& Magnusson MU (1993) Effect of ammonium sulfate on absorption of imazethapyr by quackgrass (Elytrigia repens) and maize (Zea mays) cell suspension cultures. Weed Science, 41:325-334.

Hopkins WG (1995) Introduction to plant physiology. New York, John Wiley. 464p.

Jordan DL, York AC, Griffin JL, Clay PA, Vidrine PR \& Reynolds DB (1997) Influence of application variables on efficacy of glyphosate. Weed Technology, 11:354-362.

Kozlowski LA (2001) Aplicação seqüencial de herbicidas de manejo na implantação da cultura do feijoeiro comum em sistema de plantio direto. Revista Brasileira de Herbicidas, 2:49-56.

MacIsaac SA, Paul RN \& Devine MD (1991) A scanning electron microscope study of glyphosate deposits in relation to foliar uptake. Pesticide Science, 31:53-64.

Malavolta E (1980) Elementos da nutrição mineral de plantas. São Paulo, Agronômica Ceres. 252p.

Monquero PA, Christoffoleti PJ, Osuna MD \& De Prado, RA (2004) Absorção, translocação e metabolismo do glyphosate por plantas tolerantes e suscetíveis a este herbicida. Planta Daninha, 22:445-451.

Nalewaja JD, Matysiak R \& Freeman TP (1992) Spray droplet residual of glyphosate in various carriers. Weed Science, 40:576-589.

Nielsen KH \& Schjoerring JK (1998) Regulation of apoplastic $\mathrm{NH}_{4}^{+}$concentration in leaves of oilseed rape. Plant Physiology, 118:1361-1368.

Nurse RE, Hamill AS, Kells JJ \& Sikkema PH (2008) Annual weed control may be improved when AMS is added to below-label glyphosate doses in glyphosate-tolerant maize (Zea mays L.). Crop Protection, 27:452-458. 
Pratt D, Kells JJ \& Penner D (2003) Substitutes for ammonium sulfate as additives with glyphosate and glufosinate. Weed Technology, 17:576-581.

Ramsdale BK, Messersmith CG \& Nalewaja JD (2003) Spray volume, formulation, ammonium sulfate, and nozzle effects on glyphosate efficacy. Weed Technology, 17:589-598.

Rodrigues BN \& Almeida FS (2005) Guia de herbicidas. 5 ${ }^{\mathrm{a}}$ ed. Londrina. 592p.

Ruiter HD \& Meinen E (1996) Adjuvant-increased glyphosate uptake by protoplasts isolated from quackgrass Elytrigia repens (L.) Nevski. Weed Science, 44:38-45.

Salas-Pino PAG (1996) Efeito de adjuvantes, volume de calda e qualidade da água na eficácia do herbicida glyphosate. Dissertação de Mestrado. Escola Superior de Agricultura "Luiz de Queiroz", Piracicaba, 79p.

Scott AJ \& Knott MA (1974) Cluster analysis method for grouping means in the analysis of variance. Biometrics, 30:507-512.

Silva JF, Ferreira LR \& Ferreira FA (2007) Herbicidas: absorção, translocação, metabolismo, formulação e misturas. In: Silva AA \& Silva JF (Eds.) Tópicos em manejo de plantas daninhas. Viçosa, Editora UFV. p.149-188.
Silva PRF \& Stutte CA (1981) Nitrogen volatilization from rice leaves. II. Effects of source of applied nitrogen in nutrient culture solution. Crop Science, 21:913-916.

Sodek L (2004) Metabolismo do nitrogênio. In: Kerbauy GB (Ed.) Fisiologia vegetal. Rio de Janeiro, Guanabara Koogan. p.94113.

Thelen KD, Jackson EP \& Penner D (1995) The basis for the hard-water antagonism of glyphosate activity. Weed Science, 43:541-548.

Timossi PC, Durigan JC \& Leite GJ (2006) Eficácia de glyphosate em plantas de cobertura. Planta Daninha, 24:475-480.

Wanamarta GD \& Penner D (1989) Foliar absorption of herbicides. Weed Science, 4:215-231.

Witte CP, Tiller SA, Taylor MA \& Davies HV (2002) Leaf urea metabolism in potato. Urease activity profile and patterns of recovery and distribution of ${ }^{15} \mathrm{~N}$ after foliar urea application in wild-type and urease-antisense transgenics. Plant Physiology, 128:1129-1136.

Young BG, Knepp AW, Wax LM \& Hart SE (2003) Glyphosate translocation in common lambsquarters (Chenopodium album) and velvetleaf (Abutilon theophrasti) in response to ammonium sulfate. Weed Science, 51:151-156. 